\title{
The UK sugar tax - a healthy start?
}

\author{
C. M. Jones ${ }^{1}$
}

\section{In brief}

Argues that there is no place for carbonated drinks, neither sugared nor sugar free, in a healthy diet.
Suggests the proposed levy on sugar-sweetened beverages (SSBs) is welcome as a potential contributor to better dental health.
Proposes that influences such as the Common Agricultural Policy and the Transatlantic Trade and Investment Partnership may negate the dental benefits of the sugar levy.

The unexpected announcement by the UK Chancellor of the Exchequer of a levy on sugar sweetened beverages (SSBs) on the 16 March 2016, should be welcomed by all health professionals. This population based, structural intervention sends a strong message that there is no place for carbonated drinks, neither sugared nor sugar-free, in a healthy diet and the proposed levy has the potential to contribute to both general and dental health. The sugar content of drinks exempt from the proposed sugar levy will still cause tooth decay. Improving the proposed tax could involve a change to a scaled volumetric tax of added sugar with a lower exemption threshold. External influences such as the Common Agricultural Policy and the Transatlantic Trade and Investment Partnership may negate the benefits of the sugar levy unless it is improved. However, the proposed UK sugar tax should be considered as a start in improving the nation's diet.

Given the UK obesity epidemic and the rise in diet-related comorbidities, including dental caries, like many I initially welcomed the announcement of a UK tax on sugar sweetened beverages (SSBs) in the Westminster budget on 16th March 2016. The Chancellor stated, 'I am not prepared to look back at my time here in this Parliament [...] and say to my children's generation, I'm sorry. We knew there was a problem with sugary drinks. We knew it caused disease, but we ducked the difficult decisions and we did nothing. We are introducing the levy on the industry which means that companies can [...] promote low-sugar or no-sugar brands.' A masterful diversion that, some cynics have said, deflected attention from a budget that took from the disabled and gave to the rich.

The early ban on smoking in public places and legislating for minimum unit pricing on alcohol showed that the Scottish Parliament is not afraid to be radical over legislation on public health issues. However, it took a Conservative UK Chancellor to introduce a SSB tax.

The sugared soft drinks levy (is it a levy

${ }^{1}$ Honourary Senior Lecturer, Edinburgh Dental Institute, Lauriston Place, Edinburgh, EH3 9HA

Correspondence to: C. Jones

Email: colwyn.jones@nhs.net

Refereed Paper. Accepted 13 May 2016

DOI: $10.1038 /$ sj.bdj.2016.522

${ }^{\circ}$ British Dental Journal 2016; 221: 59-60 because governments don't like taxes?) is not a silver bullet. I understand that a bullet made of silver is the only way to kill a werewolf; a human being who can assume the form of a wolf, while retaining human intelligence, typically under a full moon. A mythical member of the 'undead' curiously popular in today's youth culture, not a wicked health problem facing every developed and increasingly developing country. There is no simple and seemingly magical solution to the problems caused by the neoliberal diet. ${ }^{2}$ So aside from highlighting the health problems of sugared drinks and obesity to the UK population (the Government have taxed it, so it must be a genuine problem) will a tax on home produced or imported sugar sweetened beverages help?

In Mexico, and other countries, there is evidence that an excise tax on sugar sweetened beverages reduces demand. ${ }^{3,4}$ Basic economics of supply and demand for goods is how trade in the world economy is thought to work; that a tax will work seems self-evident, but the precise effect is uncertain.

The sugared soft drinks levy that the Chancellor announced has a banding structure; less than $5 \mathrm{~g} / 100 \mathrm{ml}$ - no tax; 5-8 g/100 ml - basic level tax; more than $8 \mathrm{~g} / 100 \mathrm{ml}$ - higher level tax.

The tax will be introduced in 2018; two years away, 'to give companies plenty of space to change their product mix. Is this reformulation for harm reduction, or is it what used to be called food adulteration?
After the euphoria (but not a sugar rush) of the announcement, my first question was why did the Chancellor adopt these levels of sugar for the tax?

Sugar-sweetened beverages are immensely profitable. They are cheap to manufacture, the high sugar content gives a long shelf life, they are marketed aggressively through multiple outlets and they sponsor high profile niche sports. Concerned about profits, the processed food and beverage industries have opposed any form or regulation or taxation. Their tactics were those used by the tobacco industry, hence the suggestion that 'Sugar is the New Tobacco.'

I note that the soft drinks industry in Scotland (and I am sure elsewhere in the UK) are reported to have had meetings with The Treasury. ${ }^{6}$ The choice of content thresholds of $5 \mathrm{~g}$ and $8 \mathrm{~g}$ for the sugar tax must have come from somewhere! I can speculate that they may have been derived from the UK front of pack (FoP) nutrition labelling for pre-packed products sold through retail outlets: the voluntary UK food traffic light system rejected by the EU following intense lobbying by the food industry. The traffic light system does have an upper green threshold of $5 \mathrm{~g} / 100 \mathrm{~g}$ for low sugar foods. ${ }^{7}$

However, there was a separate FoP traffic light threshold for healthy drinks; $2.5 \mathrm{~g} / 100 \mathrm{ml}$; exactly half of the sugar content proposed by the Chancellor for the SSB tax. No wonder that the 
soft drinks industry seemed neither surprised, nor too upset!

Approaching these sugar content levels from the dental health viewpoint, we know that a $2.5 \%$ sucrose solution will drop dental plaque $\mathrm{pH}$ to below the critical level to cause demineralisation of enamel, that is, tooth decay. ${ }^{8}$ So the $5 \mathrm{~g} / 100 \mathrm{ml}$, or $50 \mathrm{~g} /$ litre ( $50 \mathrm{~g}$ is 12 teaspoons of sugar, hardly a low level), which is tax exempt, will cause tooth decay.

To avoid any confusion over percentage solutions and grams/litre, $5 \mathrm{~g} / 100 \mathrm{ml}$ is a $4.7 \%$ solution of sugar (5/105 as a percentage), $8 \mathrm{~g} / 100 \mathrm{ml}=7.4 \%$ ( $8 / 108$ as a percentage).

The more sugar you eat or drink and the more often you eat or drink sugar-containing foods the more likely you are to suffer from tooth decay. Despite recent improvements in Scotland, $31 \%$ of primary one children (5-year-olds) have experience of tooth decay which is entirely preventable. In 2014 the extraction of teeth was the most common reason children aged from 5 to 9 years had a hospital admission in Scotland. Dental erosion (tooth surface loss) is also caused by the citric or phosphoric acid added during the manufacture of carbonated drinks, even in sugar free varieties. From an obesity viewpoint, the tax free threshold of 12 teaspoons of sugar in a litre of carbonated drink (three teaspoons of sugar in a tea cup) remains habituation to a diet with an intensely sweet taste.

The 'Carbohydrates and Health Report' by The Scientific Advisory Committee on Nutrition showed that SSBs are associated with increased risk of type 2 diabetes and obesity. ${ }^{9}$ SACN concluded high-sugar beverages result in weight gain and increased body mass index (BMI) in teenagers and children, and increase the risk of developing type 2 diabetes independently of obesity.

I note that currently Coca Cola original (other brands available) has $10.6 \mathrm{~g} / 100 \mathrm{ml}$ consistently across the UK. Years ago, I was told that Scotland's second national drink, original Irn Bru (other brands available, but perhaps not with ammonium ferric citrate, Sunset Yellow and Ponceau 4R) contained more sugar than the same drink sold in England, but my recent research shows that this is an urban myth; Irn Bru seems to have $10.3 \mathrm{~g} / 100 \mathrm{ml}$ of sugar across the UK; there goes one of my best punchlines!

More interestingly Coca Cola Life is marketed in the UK with a green label and is sold as having reduced sugar compared to the original cola ( $6.7 \mathrm{~g} / 100 \mathrm{ml}$, actually $63 \%$ of the original) plus an intense sweetener called Stevia. That means it would exceed the exemption threshold and be taxed with the new sugar tax. However, in Germany Coca Cola Life only has $5 \mathrm{~g} / 100 \mathrm{ml}$ and would be exempt from the UK SSB tax. Soft drinks manufacturers already reformulate their products to suit taste and regulations in different countries. A common problem with industry trying to sell a harm reduction approach is that they can also claim they have done their bit!

Similar to the proposed tax on SSBs, UK alcohol duty has a banded structure for excise duties on cider and wine, but it means that there is no incentive for producers to reduce alcohol (or sugar) content below the upper threshold of the band; and suggests tacit government approval!

A volumetric tax, where duty is increased per gram of sugar (alcoholic spirits are taxed this way) avoids this issue. Even better would be a scaled volumetric tax (like beer) where the proportionate tax is scaled down on low sugar drinks and scaled up on high sugar drinks.

The dental and general health benefits of a scaled volumetric tax with an exemption threshold well below $2.5 \mathrm{~g} / 100 \mathrm{ml}$ are clear. So that all added sugar, in whatever form, is included and the more added the greater the tax level.

One other factor within Europe is that the price of sugar is predicted to drop in 2017 as regulation of sugar markets changes and production quotas within the EU are abolished. EU Common Agricultural Policy (CAP) has been influencing the diets of consumers by determining to a large extent the price and availability of most food. This includes European produced sugar, almost entirely from sugar beet. The 2013 CAP reforms liberalise the EU sugar market, quotas will be abolished and this will lower EU sugar prices. The liberalisation could also mean that high-fructose corn syrup (HFCS), the industrial liquid sweetener manufactured from maize or corn commonly used outside Europe to sweeten beverages, will replace sucrose from sugar beet. The result may be that the sugar tax will have little financial impact on the soft drinks industry if it absorbs any price rise.

Then there is the Transatlantic Trade and Investment Partnership (TTIP), a proposed trade agreement between the European Union and the United States, with the aim of promoting trade and economic growth. Concern has been raised about the Investor State Dispute Settlement (ISDS) system. This is the arbitration system whereby disputes between the state and investors (usually corporations) can be raised, if a company feels that the state has contravened the trade agreement. In theory, this gives corporations certainty to invest while making sure that a government will not influence profits arbitrarily.
There is concern that this system might put each country's right to regulate for the public health in jeopardy. Simply the chilling threat of the costs of fighting a claim may be enough to stop a country introducing legislation to protect the public health, such as a sugar sweetened beverage levy.

Like many welcome structural interventions aimed to reduce inequalities, the sugar levy is a good idea but perhaps set at the wrong level. While the minimum wage was almost universally welcomed, even the present UK government has now realised the original threshold was inadequate!

The sugar tax is not a silver bullet, and I also fear that with no systematic evaluation of the tax announced it could be repealed if little direct effect on obesity and other co-morbities can be demonstrated.

Food and water are essential for life, carbonated drinks and tobacco are not. There is no place for carbonated drinks, neither sugared nor sugar free, in a healthy diet. Despite all of the drawbacks, I welcome the proposed SSB tax, especially as there is ample room for improvement. As Bismarck said, 'Politics is the art of the possible.'

Finally, if you want to add sugar to your drinks, do it yourself, don't let anyone, and certainly not the food and drink industry, nanny you!

Disclaimer: The views presented in this article are solely those of the author.

1. Parliament. House of Commons Hansard archives. 2016. Available online at http://www.parliament.uk/business/ publications/hansard/commons/ (accessed March 2016).

2. Otero G, Pechlaner G, Giselle Liberman G, Gürcan E. The neoliberal diet and inequality in the United States. Soc Sci Med 2015; 142: 47-55.

3. Powel L M, Chriqui J F, Khan T, Wada R, Chaloupka F J. Assessing the potential effectiveness of food and beverage taxes and subsidies for improving public health: a systematic review of prices, demand and body weight outcomes. Obesity Rev 2013; 14: 110-128.

4. Colchero M A, Popkin B M, Rivera J A, Ng S W, Beverage purchases from stores in Mexico under the excise tax on sugar sweetened beverages: observational study. BMJ 2016; 2016: 352-361.

5 Action on Sugar. Worldwide experts unite to reverse obesity epidemic by forming 'action on sugar'. Press Release. Available online at http://www.actiononsalt. org.uk/actiononsugar/Press\%20Release \%20/120017. html (Accessed May 2016).

6. Evening Times. Cumbernauld firm AG Barr to move away from high sugar drinks in light of new tax. 2016 Available online at http://www.eveningtimes.co.uk/ news/14389000.Cumbernauld_firm_AG_Barr_to_ move_away_from_high_sugar_drinks_in_light_of_ new_tax/ (accessed April 2016).

7. Department of Health. Guide to creating a front of pack (FoP) nutrition label for pre-packed products sold through retail outlets. 2013. Available online at https:// www.gov.uk/government/uploads/system/uploads/ attachment_data/file/300886/2902158_FoP_Nutrition_2014.pdf (accessed June 2016).

8. Murray J J, Nunn J H, Steele J G. Prevention of oral disease. Oxford University Press: Oxford, 2003.

9. SACN. The Scientific Advisory Committee on Nutrition Recommendations on Carbohydrates, including Sugar and Fibre. Public Health England, 2015. https:// www.gov.uk/government/publications/sacn-carbohydrates-and-health-report (accessed April 2016). 